\title{
Phycocyanin Thermo-photostability: An Accelerated Life-test Analysis
}

\author{
Daniel A. Pérez-Rico ${ }^{1}$, Jorge Luis Alarcón-Jiménez ${ }^{1}$, Escarlett González-Morales ${ }^{1}$, Luis Felipe \\ Guerra-Álvarez ${ }^{1}$, Juan Carlos Ramírez-Vázquez ${ }^{1}$, Humberto Gutiérrez-Pulido ${ }^{2, *}$, Froylán M.E. \\ Escalante ${ }^{1, *}$
}

${ }^{1}$ Laboratory of Microbial Metabolism, Biotechnology and Environmental Department, Autonomous University of Guadalajara, AC. Av. Patria 1201, Lomas del Valle, Zapopan, Mexico 45129.

${ }^{2}$ Centro Universitario de Ciencias Exactas e Ingeniería, Universidad de Guadalajara, Gral. Marcelino García Barragán 1421, Olímpica, Guadalajara, Mexico 44430

*Corresponding author: Humberto Gutiérrez-Pulido, email: humpulido@yahoo.com, Froylán M.E. Escalante, email: froymario@edu.uag.mx

Received February 19 th 2020 ; Accepted June $10^{\text {th }}, 2020$.

DOI: http://dx.doi.org/10.29356/jmcs.v64i3.1157

\begin{abstract}
Phycocyanin is a natural blue colorant with antioxidant activity which can be safely used in food, however its rapid degradation is still a concern for food manufacturing. Phycocyanin is easily degraded when exposed to mid-temperatures and/or light. Several studies have been stablished the degradation kinetics of aqueous solutions evaluating temperature or light as accelerating factors using a first order kinetic model and, both factors have been studied by separate or fixing one of them to evaluate the combined effect. The aim of this work was to develop an empirical model able to predict the effect of temperature and light combined in the degradation ratio of this pigment at selected storage conditions. We have tested five correlation models to fit temperature, light and time data to the degradation ratio of the phycocyanin; these were statistically tested to select the more appropriate. This is a novelty in the study of accelerated life-test analysis of phycocyanin, since most of the models are based on one accelerating variable at the time and the relationship between accelerating variables has not been explored before. We were able to develop a methodology to evaluate the effect of two accelerating life factors at once using CPC as model which is highly precise and easy to apply.
\end{abstract}

Keywords: Food coloring; microalgae; natural pigment; blue pigment.

Resumen. La ficocianina es un pigmento natural color azul con actividad antioxidante que puede utilizarse de manera segura en alimentos, sin embargo, su rápida degradación sigue siendo un problema para su uso en alimentos. La ficocianina se degrada fácilmente cuando se expone a temperaturas medias o a la luz. Algunos estudios han establecido la cinética de degradación de las soluciones evaluando la temperatura o la luz como factores de aceleración usando modelos cinéticos de primer orden. Además, ambos factores han sido estudiados por separado o fijando uno de ellos para evaluar el efecto combinado. El objetivo de este trabajo fue desarrollar un modelo empírico capaz de predecir el efecto de la temperatura y la iluminación en forma combinada sobre la velocidad de degradación de la ficocianina a las condiciones de almacenamiento seleccionadas. Se probaron cinco modelos de correlación para ajustar los datos de temperatura, luz y tiempo a la velocidad de degradación de la ficocianina; dichos modelos fueron probados estadísticamente para determinar el más adecuado. Esta es una novedad en el estudio de los análisis de pruebas de vida acelerada de la ficocianina, dado que la mayoría de los modelos se basan en una sola variable acelerante a la vez y, no se han explorado las relaciones entre las 
variables de aceleración. Fuimos capaces de desarrollar una metodología altamente precisa y sencilla para evaluar el efecto de dos factores simultáneos de aceleración de la vida de la ficocianina $\mathrm{C}$ como modelo.

Palabras clave: Colorantes alimentarios; microalgas; pigmentos naturales; pigmento azul.

\section{Introduction}

Nowadays there is a wide variety of colorant additives in food industry, cosmetics and pharmaceuticals, as well as in biomedical research and clinical diagnostics. [1] These additives can be natural or synthetic, the last ones are the most used given their lower cost, the wide color spectrum, their water solubility and stability. However, the synthetic dyes have been associated to high toxic effect, allergic reactions and even carcinogenic reactions, this is why they are been replaced by natural dyes. [2-4] Therefore, modern food industry leads to an increase of cheaper, healthier and more convenient products. The use of natural ingredients, like polyunsaturated fatty acids (PUFA's) and antioxidant pigments, exhibiting high impact on functional properties is important to reduce chronic diseases incidence and microalgae are a good source to enhance the nutritional value of food and animal feed, due to their well-balanced chemical composition. [5] The use of natural pigments for the industry is increasing every day given the worldwide concern on the adverse effects of synthetic pigments in food. Natural pigments, apart from enhancing color and improving the sensorial experience of the consumer, include the added value of nutraceutical properties such as antioxidant, anticarcinogenic and anti-inflammatory activity.

One of the most obvious and arresting characteristics of the algae is their color. In general, each phylum has its own particular combination of pigments and an individual color. These pigments function as antioxidants in the plant showing interesting parallels with their potential role as antioxidants in foods and humans. Therefore, microalgae are recognized as an excellent source of natural colorants and nutraceuticals and it is expected they will surpass synthetics as well as other natural sources due to their sustainability of production and renewable nature. [5] The potential of microalgae as a source of food coloring is limited, however, because algal-derived food coloring is non photostable and the color tends to bleach with cooking. Nevertheless, despite this limitation, the potential market for micro-algae-derived food coloring is vast [6] and scientist keep on the track looking for new microbial alternatives as the thermophilic cyanobacterias Thermosynechococcus elongatus, T. vulcanus and Synechococcus lividus able to produce thermostable pigments such as Cphycocyanins. [7] Unlike other natural colorants, the phycobilin pigments phycocyanin (blue), phycoerythrin (red), phycoerythrocyanin (orange) and allophycocyanin (green-bluish) are only found in algae.

The main source of phycobiliproteins are the cyanobacterium Spirulina (Arthrospira) for phycocyanin and the rhodophyte Porphyridium for phycoerythrin. These water-soluble pigments have a wide range of applications including food and cosmetic colors, as fluorescent tags for use in flow cytometry and immunology, as possible antioxidants in cosmetics, as a component of functional foods, as photosensitizers in photodynamic therapy for treatment of cancers and for other therapeutic benefits. [5,8,9] Phycoerythrins and phycocyanins are the major commercially important given its cost and wide application range, being C-Phycocyanin the most important, it sells for between US\$ 500 to $100,000 \mathrm{~kg}^{-1}$ depending on its purity. [8] In general, phycocyanin is used in the industrial sector as colorant for chewing gum, ice cream, beverages, milk products, candies, and cosmetics. $[4,10]$

Given the importance of phycocyanin for the food and cosmetic industries, several authors have reported the effect of different factors in the degradation of this pigment. Most of them have focused their attention on temperature, but also in the addition of stabilizers able to prolong its shelf-life. Given the sensitivity of this pigment, also light has been evaluated as a damaging factor to the properties of phycocyanin. [11-16] In their studies, Antelo et al. [2], Kannaujiya and Sinha [4], studied the thermal degradation of phycocyanin using first order models. Jespersen et al. [12] studied the thermal stability of blue pigments following a zero-order reaction kinetic assaying temperatures from 45 to $55^{\circ} \mathrm{C}$ and $\mathrm{pH} 5$ and 7, but analyzed separately. Particularly, Chen and Berns [15] compared the structural stability of phycocyanin coming from thermophilic, mesophilic, psychrophilic and halophile blue-green algae using the free energy as reference. Also, González - Ramírez et al. [3] studied the denaturation of the phycocyanin by measuring the changes in the $\alpha$-helix of the protein subject 
to several $\mathrm{pH}$, finding that this protein is more stable than other phycoerythrin proteins. On the other hand, the study of $\mathrm{Wu}$ et al. [13] reflects the analysis of stability of the food grade phycocyanin under variations on $\mathrm{pH}$, temperature, light and edible stabilizers, however, all these variables were set and studied apart. Besides, in their study Chentir et al. [17] when analyzed several properties of phycocyanin, analyzed its thermal stability varying the pigment concentration in sodium phosphate buffer $(\mathrm{pH} 6.0)$ at $60{ }^{\circ} \mathrm{C}$, measuring the relative concentration of the phycocyanin thru time, reporting stability of the protein below $50^{\circ} \mathrm{C}$, but no mathematical model was used. Similarly, Sarada et al. [10] studied the thermal stability of the pigment under several $\mathrm{pH}$ conditions using buffer solutions, nonetheless no mathematical model is offered.

We consider that an alternative appropriate methodology is that of accelerated life-tests analysis; it consist in test an article or product at higher-than-usual levels of certain accelerating variables to obtain information about the failure-time distribution or degradation distribution at specified "use" levels of these variables. [18] In this report we present the accelerated life-test methodology using correlation models to describe the loss of pigment thru time affected by several combinations of temperature and light exposure during storage. This is a simple and validated methodology not reported before to analyze the thermalphotodegradation of phycocyanin, which can be applied to many other pigments during storage.

\section{Experimental}

\section{Phycocyanin solution}

The phycocyanin food grade powder (purity ratio $\mathrm{OD}_{620} / \mathrm{OD}_{280}=0.75$ ) $[2,13]$ from Arthrospira sp. was kindly provided by Biotecnología Mexicana de Microalgas S.A. de C.V. This was dissolved in distilled water at $5 \mathrm{mg} / \mathrm{mL}$ and sterilized by filtration $(0.45 \mu \mathrm{m})$. The optical density (OD) of the phycocyanin filtered solution was measured at 652 and $618 \mathrm{~nm}$ to determine the concentration of C-Phycocyanin (CPC). Individual concentrations were computed as previously reported $[19,20]$ :

$$
C P C=\frac{A b s_{618}-\left(0.474 * A b s_{652}\right)}{5.34}
$$

\section{Syn Accelerated Life Test Assays}

There were prepared nine test tubes with $10 \mathrm{~mL}$ of phycocyanin solution $(333 \pm 4 \mu \mathrm{g} / \mathrm{mL})$ for each experimental treatment (Table 1). Briefly, four temperatures were tested: 5, 18, 44 and $57 \pm 1{ }^{\circ} \mathrm{C}$ in combination with three light intensities $0,65,130 \mu \mathrm{molm}^{-2} \mathrm{~s}^{-1}$ (PPFD). The selection of temperatures and light levels are in accordance with other authors [2-4]. We have selected the temperature of $5^{\circ} \mathrm{C}$ and complete darkness as control temperature and light conditions to keep the pigment color since it is predicted that low temperatures preserve the concentration of the pigment in solution. The remaining levels were stablished to accelerate the degradation of the phycocyanin. Temperature was controlled using a microbial incubator and light was provided with led lamps at the required conditions. Samples from each experimental treatment were taken at different time intervals according with the expected degradation time lapse (Table 1) and the $\mathrm{OD}_{652}$ and $\mathrm{OD}_{628} \mathrm{~nm}$ were measured. It was not added any $\mathrm{pH}$ stabilizer since the intention of this work was to evaluate the pigment degradation by light and temperature. Degradation is considered as the decrement in the concentration of the CPC $\left(Y_{t}\right)$ which is dependent on temperature $(H)$, light intensity $(L)$ and exposure time $(T)$, then $Y_{t}=$ $O D(t, H, L)$; as long as these three variables increase the $Y_{t}$ diminishes. 
Table 1. Experimental design for phycocyanin degradation assays including the different levels of temperature, light and time assayed.

\begin{tabular}{|c|c|c|c|c|c|c|}
\hline $\boldsymbol{C}$-Temperature $\left(^{\circ} \mathbf{C}\right)$ & $\boldsymbol{L}$-Light $\left(\boldsymbol{\mu}\right.$ molm $\left.^{-2} \mathbf{s}^{-\mathbf{1}}\right)$ & \multicolumn{5}{|c|}{$\boldsymbol{T}$-Time (h) to measure phycocyanin concentration } \\
\hline 5 & 0 & 72 & 144 & 216 & 288 & 360 \\
\hline 5 & 65 & 72 & 144 & 216 & 288 & 360 \\
\hline 5 & 130 & 72 & 144 & 216 & 288 & 360 \\
\hline 18 & 0 & 48 & 96 & 120 & 168 & 216 \\
\hline 18 & 65 & 48 & 96 & 120 & 168 & 216 \\
\hline 18 & 130 & 48 & 96 & 120 & 168 & 216 \\
\hline 44 & 0 & 2 & 4 & 6 & 8 & 10 \\
\hline 44 & 65 & 2 & 4 & 6 & 8 & 10 \\
\hline 44 & 130 & 2 & 4 & 6 & 8 & 10 \\
\hline 57 & 0 & 1 & 2 & 3 & 4 & 5 \\
\hline 57 & 65 & 1 & 2 & 3 & 4 & 5 \\
\hline 57 & 130 & 1 & 2 & 3 & 4 & 5 \\
\hline
\end{tabular}

\section{Statistical Analysis}

For all the nine tubes in a treatment, a series of $Y_{t}$ values were obtained from each test tube to generate a degradation path for that specific treatment and replica, Table 1. The statistical analysis was carried out in two stages. In the first stage, a model was chosen to adequately describe each of the generated paths. This model, $f(t)$, varies according to time and its decay rate is determined by the value of its parameters, $\lambda_{\mathrm{i}}$. The best model fitting the experimental paths was selected. In the second stage, there was investigated the effect each one of the two physical parameters assayed $(H, L)$ in the parameters of the selected model in stage one to determine how these two factors affected the degradation rate of the phycocyanin.

For each test tube (assay), subject to specific conditions of temperature $(H)$ and light intensity $(L)$, the $Y_{t}$ value was computed as the ratio between the OD at the specified time and the value of OD at the beginning of the experiment $(\mathrm{T}=0)$, Equation 2 . At $T=0$ the computed ratio is equal to 1 , followed by a decaying ratio in the course of the experimental time. This leads to measure the color degradation ratio as function of time $(t)$ and, to isolate the variation among replicates from equal experimental conditions $(H, L)$.

$$
Y_{t}=\frac{O D(t, H, L)}{O D(0, H, L)}
$$

In 102 of the 108 test tubes the phycocyanin degradation could be adequately monitored. For each trajectory of these 102 experimental units several mathematical models were tested to determine the most appropriate describing the pigment degradation as function of time and considering the different experimental conditions $(H, L)$. The main models studied are shown in Table 2. We opted for these degradation models which are included in the category of empirical acceleration models [18] given the difficulty of developing a model based on the physical / chemical theory for the decrease of $\mathrm{OD}(t, H, L)$. All models in Table 2 are presented in decreasing order of the number of terms of their parameters in such a way that the values of these parameters reflect the phycocyanin degradation ratio $\left(Y_{t}\right)$ as function of $\mathrm{H}$ and L. Models No. 4 and No. 5 correspond to the survival functions of Weibull and exponential distributions, respectively [21].

For each model fitted to the degradation paths, the determination coefficient, $\mathrm{R}^{2}$, and their coefficients were computed. The most adequate model predicting the degradation paths was selected based on the 
information provided by the $\mathrm{R}^{2}$ and the number of parameters included in the model. This concluded the first stage of the analysis.

Next, the effect of acceleration factors: temperature $(H)$ and light intensity $(L)$ on the phycocyanin degradation paths $\left(Y_{t}\right)$ was studied analyzing the influence of these factors in parameters of the selected model. This analysis considered the factorial array in Table 1 and designating as response variable for each replicate of the corresponding treatment the values of the parameters of the selected model. The responses analysis was carried out using the following regression model:

$$
\log \left(\lambda_{j}\right)=\beta_{0}+\beta_{1} H+\beta_{2} L+\beta_{12} H L+\beta_{11} H^{2}+\beta_{22} L^{2}+\epsilon
$$

where, $\lambda_{\mathrm{j}}$ represents each one of the parameters for the selected model. The expression $\log \left(\lambda_{\mathrm{j}}\right)$, natural logarithm, was used to assure that $\lambda_{j}$ parameter is kept positive and preserves the decrements in the degradation path.

\section{Results and discussion}

\section{Fitting model selection}

Phycocyanin aqueous solutions were subject to several treatments resulting from the combination of four temperatures $\left(5,18,44\right.$ and $\left.57{ }^{\circ} \mathrm{C}\right)$ and three light intensities $\left(0,65\right.$ and $\left.130 \mu \mathrm{molm}^{-2} \mathrm{~s}^{-1}\right)$, a pigment concentration was tracked in several time lapses thru spectrophotometric analysis as shown in Table 1. Then, five degradation models were tested, Table 2 . After an exploratory analysis of the experimental data and the decaying paths it was decided to remove the control treatment $(H=5, \mathrm{~L}=0)$ from fitting adjustment of the tested models since this path kept constant most of the time. The remaining eleven treatments with their respective replicates (91 paths) were fitted with each model.

In general, it was observed that all tested models showed a good predictive potential; in all cases the $R^{2}$ was higher than $94.5 \%$ and in almost all cases was close to $100 \%$. However, the best fitting model was number 4, with $\mathrm{R}^{2}=96.7$ in almost all the tested cases; both parameters ( $a$ and $b$ ) influence the degradation rate. In order to simplify the predictive equation the parameter $b$ was set to be 1 generating then model No. 5 which is a simplification of model No. 4, see Table 2.

Table 2. Main models fitted to the pigment data.

\begin{tabular}{|c|c|}
\hline Model & $\boldsymbol{Y}_{\boldsymbol{t}}$ \\
\hline 1 & $a-b t^{0.5}$ \\
\hline 2 & $1 /(a+b t)$ \\
\hline 3 & $\exp (-a-b t)$ \\
\hline 4 & $\exp \left(-a t^{b}\right)$ \\
\hline 5 & $\exp (-a t)$ \\
\hline
\end{tabular}

\section{Effect of temperature and light intensity}

The averaged degradation time as function of temperature $(H)$ and light intensity $(L)$ exposure was tested following the multiple regression procedure for parameter $a$ of model 5 (Eq. 3). The final regression model for the parameter $\log (a)$ of model 5 is shown in equation 4.

$$
\log (\widehat{a})=-8.47671+0.063285 H+0.043936 L-0.000366 H^{*} L+0.000871 H^{2}-0.000145 L^{2}
$$


The corresponding variance analysis for this model is shown in Table 3. Given that $R^{2}$ was $97.2 \%$ it can be stated that temperature and light intensity explain the phycocyanin degradation ratio. The standard error of the estimate $(0.30679)$ is the base to calculate a $100(1-\alpha)$ percent confidence interval on the mean response for $\log (\mathrm{a})$; for more details please refer to Montgomery [22].

From equation 4 and Table 3 is possible to see that temperature $(H)$ has a higher impact in the pigment degradation (lose of color). However, light intensity $(L)$ also has a relevant role in the pigment degradation, as well as the interaction of temperature and light intensity $\left(H^{*} L\right)$. The quadratic parameters improve the fitting; however, they must be considered with caution outside of the experimental region for extrapolation purposes. When avoiding the quadratic parameters, the fitted model is given by equation 5 :

$$
\log (\widehat{a})=-8.65612+0.113851 H+0.0247368 L-0.000359759 H^{*} L
$$

This model has a $R^{2}=93.3 \%$ and an estimated standard error $=0.0470$, which is good enough and offers the possibility to be used for extrapolation purposes.

With equations 4 and 5 it is possible to predict the degradation time of the phycocyanin under given conditions of temperature and light $(H, L)$ into the experimental region, Table 1 . Then, it is necessary to replace the $a$ value in model number 5 . But equation 5 estimates the $a$ logarithm; to get its value in the original scale and, to preserve as estimator the expected value of $a$ [23], it comes to:

$$
\hat{a}=\exp [\log (\hat{a})] * \exp \left(\frac{\hat{\sigma}^{2}}{2}\right)
$$

where, $\hat{\sigma}$ is the estimated standard error of the variance analysis $(0.30679$, Table 3$)$. Then, the estimated time in hours $(t)$ to get a specific degradation (a portion $q$ ) of the initial concentration of phycocyanin under the specified conditions of temperature and light $(H, L)$ is computed as follows:

$$
P(I>t)=\exp (-\hat{a} t)=1-q
$$

Rearranging time $(t)$ from equation 7, the estimated time is given by:

$$
\hat{t}=-\frac{1}{\hat{a}} \ln (1-q)
$$

For example, to predict the required time to get a $25 \%$ degradation of the phycocyanin $(q=0.25)$ when the pigment solution is kept at $20^{\circ} \mathrm{C}$ and light intensity of 50 PPFD, $H=20$ and $L=50$, is necessary to use equation 5. Then $\log (a)=-5.3952653$, using this value in equation $6, \hat{a}=0.00475668$. Thus, replacing this last value in equation 8 the estimated time to get a $25 \%$ degradation of pigment in the phycocyanin solution is $60.48 \mathrm{~h}$. If half-life of the pigment is required (50\% degradation, $q=0.50)$ under the same conditions, it is necessary to wait for $145.72 \mathrm{~h}$. Figures 1 and 2 show the half-life of the phycocyanin solutions in days and hours, respectively, as function of temperature and light intensity. 


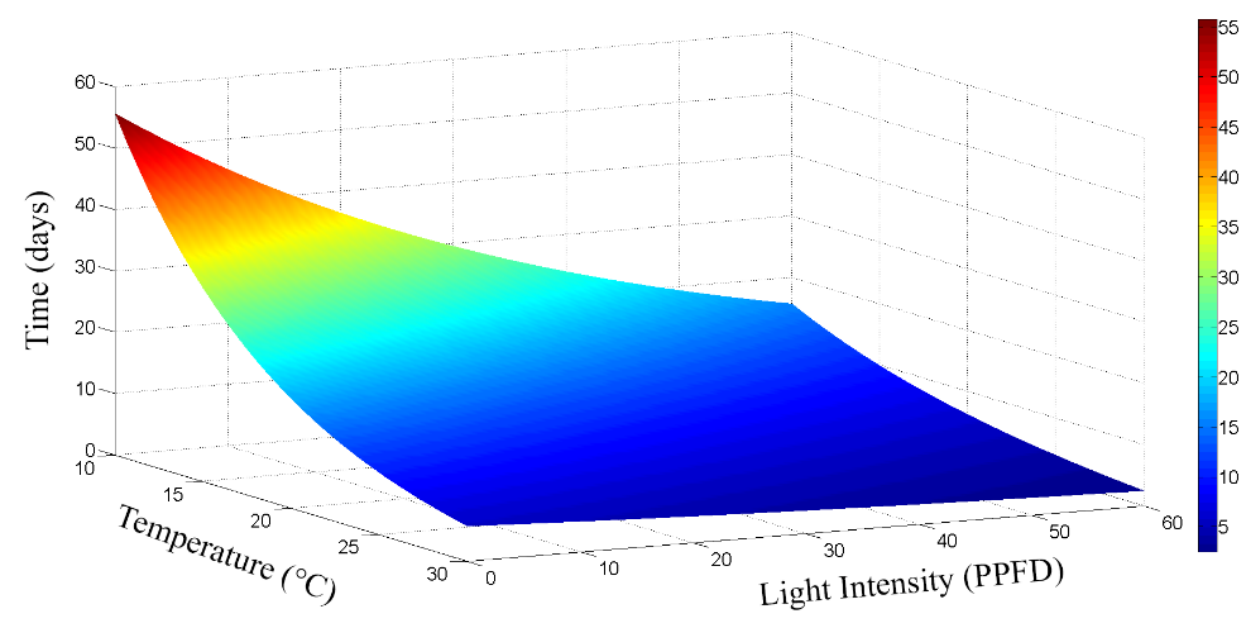

Fig. 1. Half-life of the phycocyanin solutions when stored at temperatures from 10 to $30^{\circ} \mathrm{C}$ and light intensities from 0 to $60 \mu \mathrm{molm}^{-2} \mathrm{~s}^{-1}$ (PPFD).

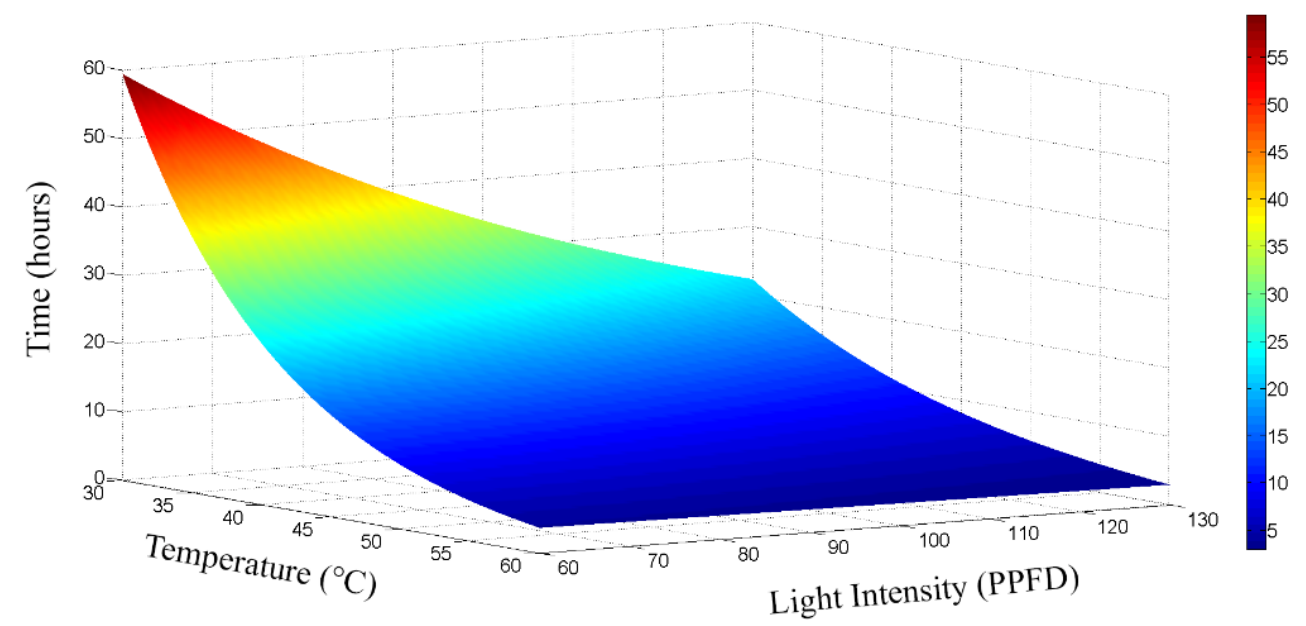

Fig. 2. Half-life of the phycocyanin solutions when stored at temperatures from 30 to $60^{\circ} \mathrm{C}$ and light intensities from 60 to $130 \mu \mathrm{molm}^{-2} \mathrm{~s}^{-1}$ (PPFD).

Table 3. Analysis of Variance for the Multiple Regression Model for parameter $\log (a)$.

\begin{tabular}{|c|c|c|c|c|c|}
\hline Source & Sum of squares & df & $\begin{array}{c}\text { Mean } \\
\text { Square }\end{array}$ & F-ratio & p-Value \\
\hline Model & 279.951 & 5 & 55.9903 & 594.88 & 0.0000 \\
\hline Residual & 8.00023 & 85 & 0.0941204 & & \\
\hline Total & 287.951 & 90 & & & \\
\hline
\end{tabular}




\begin{tabular}{|c|c|c|c|c|}
\hline Parameter & Estimate & Standard error & T-Statisitic & p-value \\
\hline Constant & -8.47671 & 0.18663 & -45.4199 & 0.0000 \\
\hline $\boldsymbol{c}:$ Temperature & 0.0632848 & 0.00973649 & 6.49976 & 0.0000 \\
\hline $\boldsymbol{l}:$ PPFD & 0.0439359 & 0.00297028 & 14.7918 & 0.0000 \\
\hline $\boldsymbol{c}^{*} \boldsymbol{l}$ & -0.00036603 & 0.0000350516 & -10.4426 & 0.0000 \\
\hline $\boldsymbol{c}^{\mathbf{2}}$ & 0.000871128 & 0.00013429 & 6.48692 & 0.0000 \\
\hline $\boldsymbol{l}^{\mathbf{2}}$ & -0.000145387 & 0.0000172 & -8.45272 & 0.0000 \\
\hline
\end{tabular}

R-squared $=97.2 \% ;$ R-squared $(\operatorname{adj})=97.1 \% ;$ Std. error est. $=0.30679$

\section{Disussion}

In this study 5 correlation models for phycocyanin degradation were tested. All models were accurate in predicting the degradation pathway of phycocyanin solutions with determination coefficients $\left(\mathrm{R}^{2}\right)$ above $94.5 \%$, however, the first four models include three parameters and, model five is derived from model No. 4 (Weibull) and needs only two parameters, since term $b$ in model No.4 is equal to 1 . Model No. 5 corresponds to the survival functions of exponential distributions, and it showed good adjustment capacity in all the tested cases, as shown in Figures 3 and 4, and Table 4. Only four of the 91 curves had their $\mathrm{R}^{2}$ lower than $80 \%$, then model 5 was considered as suitable and it was selected as final. Then, all the comparisons and conclusions below are based on it.

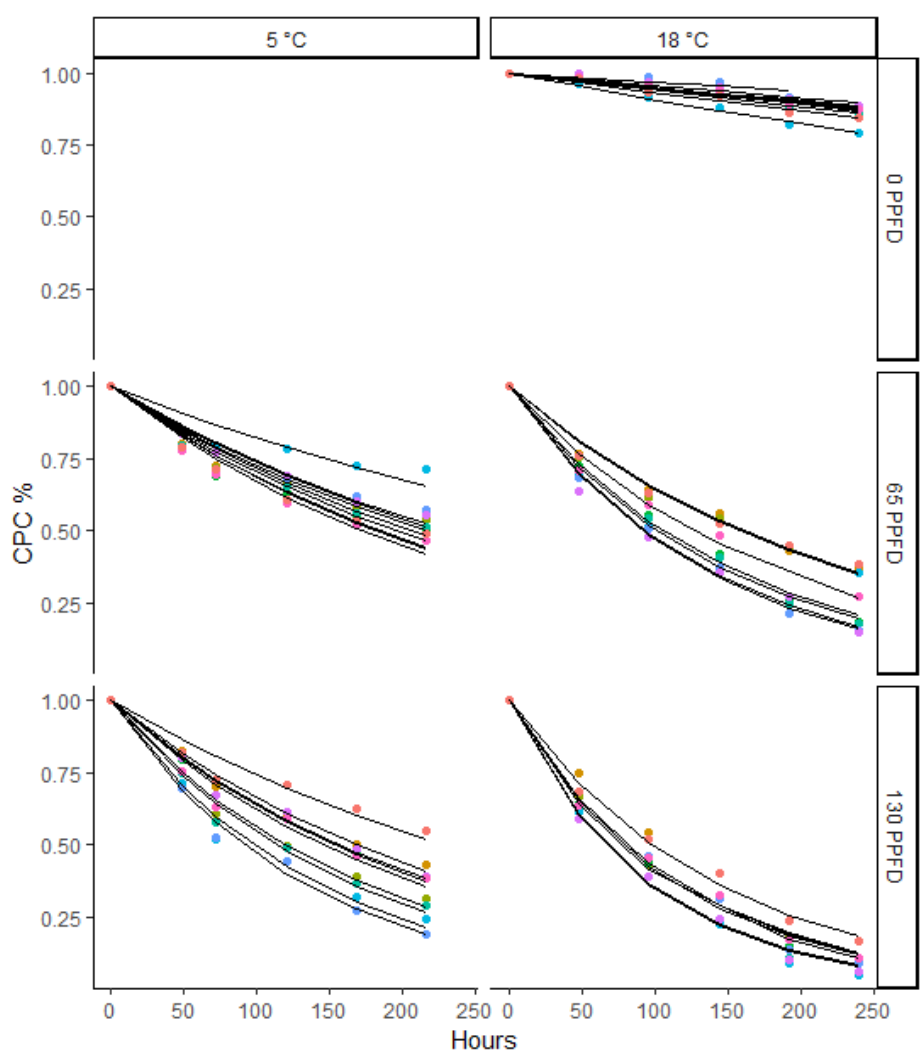

Fig. 3. Degradation curves of phycocyanin solutions stored at temperatures 5 and $18{ }^{\circ} \mathrm{C}$ at different light intensities. 


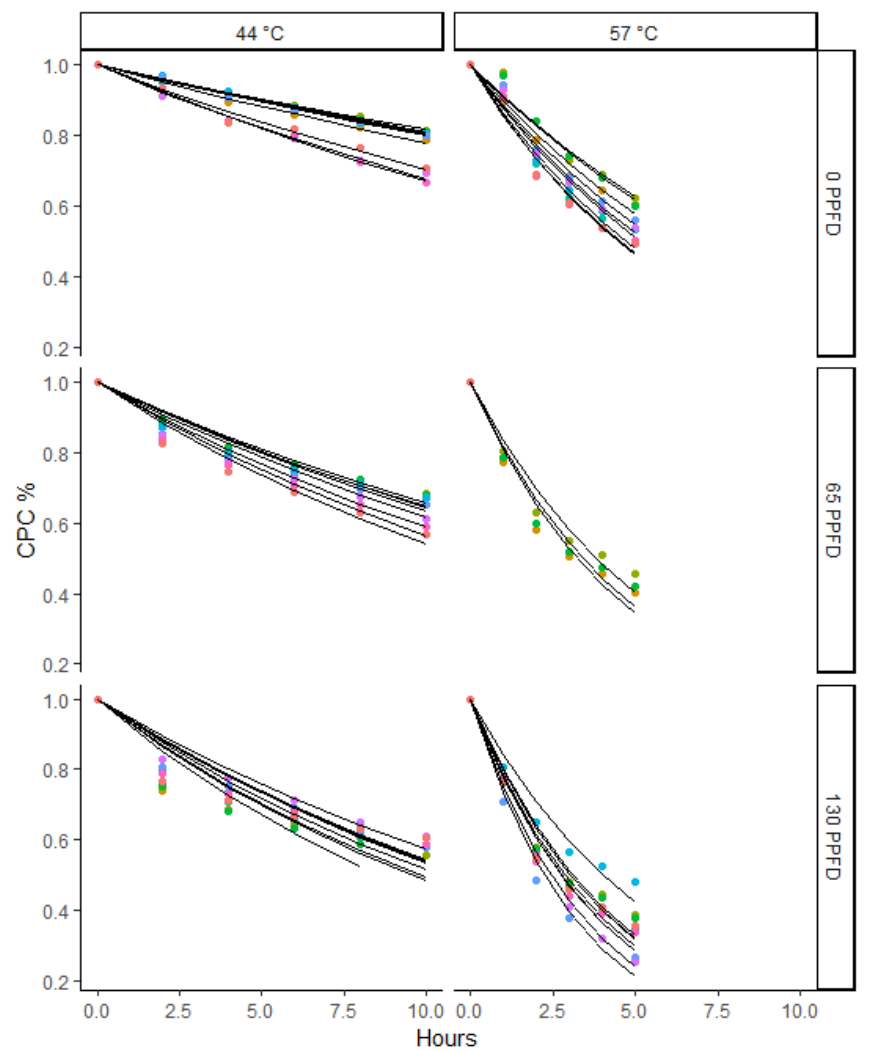

Fig. 4. Degradation curves of phycocyanin solutions stored at temperatures 44 and $57{ }^{\circ} \mathrm{C}$ at different light intensities.

Table 4. Statistics for $R^{2}$ from model No. 5 .

\begin{tabular}{|c|c|}
\hline Mean & 0.9529 \\
\hline Median & 0.9691 \\
\hline Minimum & 0.7236 \\
\hline Maximum & 0.9973 \\
\hline Percentil 95 & 0.9959 \\
\hline Percentil 5 & 0.8175 \\
\hline
\end{tabular}

It has been reported the degradation of C-phycocyanin depends on many factors including light, temperature, $\mathrm{pH}$ and protein concentration. [20] Then, using C-phycocyanin in the food industry where food processing mostly requires high temperatures, is limited in its natural form and most of the time requires additives. In previous studies, the half-life of crude $\mathrm{CPC}$ at $50{ }^{\circ} \mathrm{C}$ and $60^{\circ} \mathrm{C}$ was determined to be 9.5 and 0.106 hours (6.41 min), respectively. [2] In another study at $60{ }^{\circ} \mathrm{C}$, using the same kinetic model the predicted halflife was 0.19 hours (11.55 minutes); [24] this last result is in agreement with that presented by Wu et al. [13] where the relative concentration of phycocyanin was around $60 \%$ after 4 minutes. By using the model presented here, and assuming that $\mathrm{CPC}$ under study is in complete darkness, then the corresponding half-life at $50{ }^{\circ} \mathrm{C}$ would be $12.8 \mathrm{~h}$ and, at $60{ }^{\circ} \mathrm{C}$ would be 3 hours. Our results agree at $50{ }^{\circ} \mathrm{C}$ with that presented by Antelo et al.[2], but when considering $60^{\circ} \mathrm{C}$ we have a considerable discrepancy, from 3 hours with this model to some few minutes in their studies. However, our result is similar to that presented recently by Chentir et al. [17], they 
reported a final $63 \%$ remaining CPC from $0.5 \mathrm{mg} / \mathrm{L}(500 \mu \mathrm{g} / \mathrm{mL})$ after two hours of exposure at $60{ }^{\circ} \mathrm{C}$, the study concludes at two hours, so no more information can be extracted from this; by using the model presented here after $2.7 \mathrm{~h}$ it would be $63 \% \mathrm{CPC}$ remaining. For instance, discrepancies between results could be attributed to differences in the assay conditions, but mostly to CPC concentration and the culture condition used. Antelo et al. and Cavalcante et al. used Spirulina platensis LEB-52 cultivated in $20 \%$ Zarrouck in open pond reactors; in our study as well as in Chentir et al., CPC came from Arthrospira sp. in non-diluted Zarrouck medium; both strains are named indistinctly as Spirulina or Arthrospira, a more detailed discussion on this can be found in Sili et al. [25]. This leads us to think that culture medium composition might also affect the thermal stability of the CPC. Which is true in all cases is that degradation of phycocyanin is accelerated at higher temperatures, i.e. at $50{ }^{\circ} \mathrm{C}$ the estimated half-life of $\mathrm{CPC}$ is 12.8 hours but increasing only $10{ }^{\circ} \mathrm{C}$ (at $60{ }^{\circ} \mathrm{C}$ ) the half-life is reduced to 4.1 hours. A more drastic decay is observed with the compared models.

We have analyzed also the effect of light on the CPC degradation kinetic. As stated before, temperature and light are accounted for as the most important variables in terms of storage in many food industries. [11] Other authors have previously analyzed the impact of light exposure on CPC [11-14]. Except for Chou and Lee [11], the other authors analyzed the effect of light separately from temperature and kept it constant showing that light exposure accelerates the pigment degradation. In their study, Choi and Lee [11] refer a more accelerated degradation of CPC when temperature and light are combined; however, in their study light intensity is fixed to no-light exposure or a $20 \mathrm{~W}$ white fluorescent lamp visible light exposure and CPC solutions were subject to three different temperatures $\left(4,25\right.$ and $\left.40{ }^{\circ} \mathrm{C}\right)$ in the rank of those temperatures studied here. By their own side, Colla et al. [14] analyzed the thermal and photostability of the antioxidant activity of CPC from $S$. platensis. Consistently with that previously reported by the other authors mentioned above and, with this study, light largely accelerates the CPC degradation, either for color or antioxidant activity.

We have shown that phycocyanin concentration in aqueous solutions decreased in a time and temperature-dependent manner, as mentioned above, despite of the culture conditions, the use of additives or $\mathrm{pH}$ control $[2,4,12,13,24]$, temperature seems to be the most important factor in the degradation of CPhycocyanin and, in consequence, its greater limiting factor to its use in food processing. Despite of the frequent number of studies related to temperature degradation of CPC and the efforts to reduce it or even the look for new sources of the pigment using thermostable microorganisms as Thermosynechococcaceae sp. [7], all these studies have considered a first order degree kinetic model to describe this phenomena, but this model does not lead to evaluate the effect of interaction on a second factor which is considered as prejudicial to CPC as temperature, light exposure. The study of the relationship between accelerating variables and the actual failure mechanism is usually extremely complicated. [18] Then, this could be the reason why most of the acceleration models include only one accelerating factor at the time.

The proposed models here, all five were able to predict with high accuracy the interaction effect of light and temperature on the degradation of $\mathrm{CPC}$, but we opted for the simplest one, the exponential model. More than only predicting the combined effect of light and temperature on CPC degradation, we have proposed a feasible methodology to be used in accelerated-life test analysis in many other applications where more than one factor is influencing the shelf-life of the product.

\section{Conclusion}

In conclusion, we suggest that in the list of factors which have been reported to have an impact on the degradation of phycocyanin, i.e. temperature, light, $\mathrm{pH}$, additives and protein concentration of the solution, another important factor that should be considered is the microbial strain and the culture conditions. Besides, it should not lose sight that interaction among factors is as important as the individual factors in pigment degradation; then we suggest the use of shelf-life analysis considering these interactions to have another vision of the pigment degradation phenomena. As we have shown here, the correlation models are able to predict the simple and combined effects of factors in a simple fashion with high predictive accuracy. 


\section{Acknowledgments}

All the authors express their gratitude to the people from Biotecnología Mexicana de Microalgas S.A. de C.V., specially to Mr. Guillermo Vega Valero, for kindly provide us the phycocyanin used in this study. This research did not receive any specific grant from funding agencies in the public, commercial, or not-for-profit sectors.

\section{References}

1. Dasgupta, C. N., in: Algal Biorefinery: An Integrated Approach, Das, D., Ed., Springer International Publishing: Cham, 2015, 253-276. https://doi.org/10.1007/978-3-319-22813-6_12.

2. Antelo, F. S., Costa, J. A. V., Kalil, S. J. Biochem. Eng. J. 2008, 41 (1), $43-47$. https://doi.org/10.1016/j.bej.2008.03.012.

3. González-Ramírez, E., Andújar-Sánchez, M., Ortiz-Salmerón, E., Bacarizo, J., Cuadri, C., MazzucaSobczuk, T., Ibáñez, M. J., Cámara-Artigas, A., Martínez-Rodríguez, S. Food Biophys, 2014, 9 (2), 184-192. https://doi.org/10.1007/s11483-014-9331-x.

4. Kannaujiya, V. K., Sinha, R. P. J. Appl. Phycol. 2016, 28 (2), 1063-1070. https://doi.org/10.1007/s10811-015-0638-x.

5. Gouveia, L., Batista, A. P., Sousa, I., Raymundo, A., Bandarra, N. M., in: Food Chemistry Research Developments, Papadopoulos, K. N., Ed., Nova Publishers, 2008, 75-112.

6. Priyadarshani, I., Rath, B. Journal of Algal Biomass Utilization 2012, 3 (4), 89-100. https://doi.org/10.1016/j.(73).

7. Liang, Y., Kaczmarek, M. B., Kasprzak, A. K., Tang, J., Shah, M. M. R., Jin, P., Klepacz-Smółka, A., Cheng, J. J., Ledakowicz, S., Daroch, M. Algal Res. 2018, 35 (August), 223-235. https://doi.org/10.1016/j.algal.2018.08.037.

8. Borowitzka, M. A. J. Appl. Phycol. 2013, 25 (3), 743-756. https://doi.org/10.1007/s10811-013-99839.

9. D’Alessandro, E. B., Antoniosi Filho, N. R. Renew. Sustain. Energy Rev. 2016, 58, 832-841. https://doi.org/10.1016/j.rser.2015.12.162.

10. Sarada, R., Pillai, M. G., Ravishankar, G. Process Biochem. 1999, 34 (8), 795-801. https://doi.org/10.1016/S0032-9592(98)00153-8.

11. Choi, W. Y., Lee, H. Y. Appl. Sci. 2018, 8 (9). https://doi.org/10.3390/app8091662.

12. Jespersen, L., Strømdahl, L. D., Olsen, K., Skibsted, L. H. Eur. Food Res. Technol. 2005, 220 (3-4), 261-266. https://doi.org/10.1007/s00217-004-1062-7.

13. Wu, H. L., Wang, G. H., Xiang, W. Z., Li, T., He, H. Int. J. Food Prop. 2016, 19 (10), 2349-2362. https://doi.org/10.1080/10942912.2015.1038564.

14. Colla, L. M., Bertol, C. D., Ferreira, D. J., Bavaresco, J., Costa, J. A. V., Bertolin, T. E. Brazilian J. Biol. 2017, 77 (2), 332-339. https://doi.org/10.1590/1519-6984.14315.

15. Chen, C. H., Berns, D. S. Biophys. Chem. 1978, 8 (3), 203-213. https://doi.org/10.1016/03014622(78)87002-1.

16. (Chaiklahan, R., Chirasuwan, N., Bunnag, B. Process Biochem. 2012, 47 (4), 659-664. https://doi.org/10.1016/j.procbio.2012.01.010.

17. Chentir, I., Hamdi, M., Li, S., Doumandji, A., Markou, G., Nasri, M. Algal Res. 2018, 35 (May), 395-406. https://doi.org/10.1016/j.algal.2018.09.013.

18. Escobar, L. A., Meeker, W. Q. Stat. Sci. 2006, 21 (4), 552-577. https://doi.org/10.1214/088342306000000321.

19. Liu, Y., Feng, Y., Lun, J. Food Bioprod. Process. 2012, 90 (2), 111-117. https://doi.org/10.1016/j.fbp.2011.08.002.

20. Pan-utai, W., Kahapana, W., Iamtham, S. J. Appl. Phycol. 2018, 30 (1), 231-242. https://doi.org/10.1007/s10811-017-1155-x. 
21. Meeker, W. Q., Escobar, L. A. Statistical Methods and Realiability Data, John Wiley \& Sons, 2014. 22. Montgomery, D., Peck, E., Vining, G. Introduction to Linear Regression Analysis, 5th ed., Wiley: Hoboken, NJ, USA, 2012.

23. Newman, M. C. Environ. Toxicol. Chem. 1993, 12 (6), 1129-1133. https://doi.org/10.1002/etc.5620120618.

24. Braga, A. R. C., Figueira, F. da S., Silveira, J. T. da, Morais, M. G. de, Costa, J. A. V., Kalil, S. J. J. Food Process 2016, 40 (6), 1264-1269. https://doi.org/10.1111/jfpp.12711.

25. Sili, C., Torzillo, G., Vonshak, A. in: Ecology of Cyanobacteria II; Whitton, B. A., Ed., Springer Netherlands: Dordrecht, 2012, 677-705. https://doi.org/10.1007/978-94-007-3855-3_25. 